\title{
Placental abruption and long-term maternal cardiovascular disease mortality: a population-based registry study in Norway and Sweden
}

\author{
Lisa DeRoo ${ }^{1}$ Rolv Skjærven ${ }^{1,2} \cdot$ Allen Wilcox $^{3} \cdot$ Kari Klungsøyr $^{1,2}$ • \\ Anna-Karin Wikström ${ }^{4,6} \cdot$ Nils-Halvdan Morken ${ }^{1,5} \cdot$ Sven Cnattingius ${ }^{6}$
}

Received: 21 January 2015/ Accepted: 3 July 2015/Published online: 16 July 2015

(C) The Author(s) 2015. This article is published with open access at Springerlink.com

\begin{abstract}
Women with preeclamptic pregnancies have increased long-term cardiovascular disease (CVD) mortality. We explored this mortality risk among women with placental abruption, another placental pathology. We used linked Medical Birth Registry and Death Registry data to study CVD mortality among over two million women with a first singleton birth between 1967 and 2002 in Norway and 1973 and 2003 in Sweden. Women were followed through 2009 and 2010, respectively, to ascertain subsequent pregnancies and mortality. Cox regression analysis was used to estimate associations between placental abruption and cardiovascular mortality adjusting for maternal age, education, year of the pregnancy and country. There were 49,944 deaths after an average follow-up of 23 years, of which 5453 were due to CVD. Women with placental abruption in first pregnancy $(n=10,981)$ had an
\end{abstract}

Lisa DeRoo

Lisa.De.Roo@igs.uib.no

1 Department of Global Public Health and Primary Health Care, University of Bergen, Postboks 7804, 5018 Bergen, Norway

2 Medical Birth Registry of Norway, Norwegian Institute of Public Health, Bergen, Norway

3 National Institute of Environmental Health Sciences, National Institutes of Health, Research Triangle Park, NC, USA

4 Department of Women's and Children's Health, Uppsala University, Uppsala, Sweden

5 Department of Clinical Sciences, University of Bergen, Bergen, Norway

6 Clinical Epidemiology Unit, Department of Medicine, Karolinska University Hospital and Karolinska Institute, Stockholm, Sweden increased risk of CVD death (hazard ratio 1.8; $95 \%$ confidence interval 1.3, 2.4). Results were essentially unchanged by excluding women with pregestational hypertension, preeclampsia or diabetes. Women with placental abruption in any pregnancy $(\mathrm{n}=23,529)$ also had a 1.8 -fold increased risk of CVD mortality (95\% confidence interval $1.5,2.2)$ compared with women who never experienced the condition. Our findings provide evidence that placental abruption, like other placental complications of pregnancy, is associated with women's increased risk of later CVD mortality.

Keywords Placental abruption - Cardiovascular disease . Women $\cdot$ Mortality

\section{Introduction}

Cardiovascular disease (CVD) is the leading cause of death for women globally [1]. Traditional risk factors and scoring systems underestimate women's CVD risk resulting in lost opportunities for primary prevention $[2,3]$. Some pregnancy complications may be signs of subclinical endothelial dysfunction or vascular disease and thus provide insight into a woman's long-term risk of developing CVD $[4,5]$. It is well established, for example, that women with a history of preeclampsia have an increased risk of CVD later in life [6-8]. A previous study in Norway found an increased risk of cardiovascular disease death among women with preeclampsia in the first pregnancy, particularly among mothers who did not have any additional pregnancies [9].

Placental abruption is an uncommon but potentially serious pregnancy complication involving the premature detachment of the placental lining from the uterus before 
delivery [10]. Affecting 0.4-1\% of pregnancies, abruption is a major cause of perinatal death and maternal morbidity. Fetal survival depends on the severity of the abruption and gestational age, with perinatal mortality in the range of 9-12\% in high income countries and up to $60 \%$ in settings with inadequate neonatal facilities [10, 11]. The immediate risks to the mother, depending on severity, include obstetric hemorrhage, disseminated intravascular coagulation, renal failure, and in rare cases, death. The etiology of abruption is not well understood. Non-pregnancy associated risk factors are cigarette smoking, alcohol and drug abuse, chronic hypertension and blood-clotting disorders; pregnancy-associated risk factors include multiparity, older age ( $\geq 35$ years) at pregnancy, abdominal trauma during pregnancy, pregnancy-induced hypertension and preeclampsia $[10,12,13]$. Like preeclampsia, the pathophysiological mechanisms of placental abruption are thought to involve problems in early placental implantation resulting in uteroplacental ischemia and placental insufficiency [14-16]. Little is known about long-term health effects for women who experience abruption. We investigated placental abruption and long-term CVD mortality in a large, population-based registry study in Norway and Sweden.

\section{Methods}

We used linked data from population-based birth and cause-of-death registries to study CVD mortality risk among women giving birth in Norway and Sweden. Linkage of individual-level data was possible due to the unique national identity numbers assigned to all legal residents in each country. The Medical Birth Registry of Norway [17], established in 1967, and the Medical Birth Register of Sweden [18], established in 1973, are based on compulsory notification for live and still births. In Norway, information on all births from 16 completed weeks is recorded. In Sweden, all live births from 22 completed weeks are included in the Birth Register. Before 30 June 2008, stillbirths were included from 28 completed weeks. After that date, stillbirths were included from 22 completed weeks. The registries include prospectively collected data on maternal characteristics and medical history, complications during pregnancy, labor and delivery and conditions of the newborn. Data were recorded in a standard manner by attending midwives and physicians during prenatal visits and at delivery and hospital discharge. Medical conditions, including placental abruption and other pregnancy complications, were diagnosed by physicians and coded using the International Classification of Diseases (ICD) (8th revision for years 1967-1998 in Norway and 1973-1986 in Sweden; 9th revision for years
1987-1996 in Sweden; and 10th revision for years 1999-2009 in Norway and 1997-2010 in Sweden). Placental abruption was defined using ICD-8 codes 632.1 and 651.4, ICD-9 code 641C, and ICD-10 code O45. Mother's (and in Norway, father's) lifetime years of formal education (as of 2009 in both countries) were obtained through linkage to population-based education registers in each country.

Each woman's birth history was obtained by linking births for the period 1967-2009 in Norway and 1973-2010 in Sweden using the mother's unique national identification number (Fig. 1). We restricted the study group to women with a first singleton birth between 1967 and 2002 in Norway $(n=836,147)$ and between 1973 and 2003 in Sweden $(n=1,281,650)$ in order to be able to identify women who had second births within 7 years after the first birth. (In Norway, $95 \%$ of women with two or more births had their second within 7 years [9].) Maternal (and in Norway, paternal) deaths were identified by data linkage to the respective national Cause-of-Death Registry through December 2009 for Norway and December 2010 for Sweden. Loss of follow-up due to emigration was low $(<1 \%)$. In addition to total mortality, we analyzed deaths due to diseases of the circulatory system (ICD-8 and ICD-9 codes 390-459; ICD-10 codes I00-I99). This category was further divided into deaths from ischemic heart disease (ICD-8 and ICD-9 codes 410-414; ICD-10 codes I20-I25), cerebrovascular disease (ICD-8 and ICD-9 codes 430-438 and ICD-10 codes I60-I69), and other circulatory system diseases (all remaining circulatory system codes). Deaths from ischemic heart disease and cerebrovascular disease were combined into one category referred to as "CVD deaths" for our main analyses. We also examined nonCVD deaths (all those not included in the circulatory disease definition above).

We conducted two main sets of analyses. First, we examined placental abruption in the first pregnancy and maternal mortality. We analyzed data from Norway and Sweden separately $(n=836,147$ and $n=1,281,650$, respectively) and then pooled the data in combined analyses $(n=2,117,797)$. We used Cox proportional-hazards regression to estimate hazard ratios (HRs) and $95 \%$ confidence intervals (CIs). To enable full adjustment for the effect of age on mortality risk, we used attained age as the primary time scale with women having delayed entry into risk sets (left-censored) at the year of their first births [19, 20]. Women were followed until death or until censored at the cutoff year of 2009 in Norway and 2010 in Sweden. Models were adjusted for maternal age at first birth $(<20$, 20-24, 25-29, 30-34, 35-39, 40+ years), lifetime years of maternal education ( $\leq 9,10-12,13-14,15+$ years), and year of first birth (linear term), and, in analyses of combined data, country. 


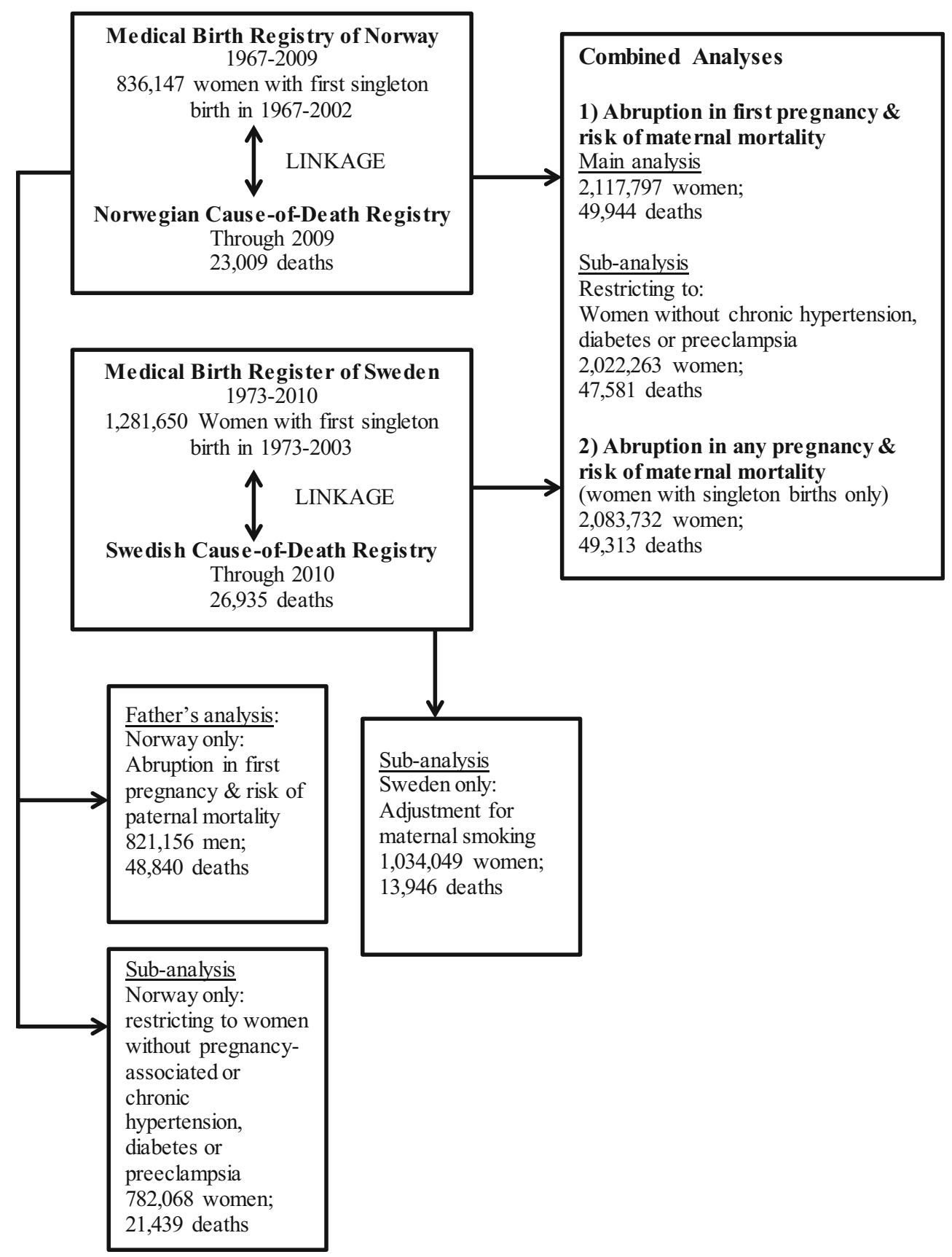

Fig. 1 Data sources and numbers of study subjects

To remove the possible effects of underlying chronic disease or other pregnancy conditions on the association between abruption and maternal mortality, we conducted analyses restricted to women without the following conditions before or during their first pregnancies: chronic hypertension, chronic or gestational diabetes mellitus, preeclampsia, and pregnancy-induced hypertension (available in Norway only). To assess possible differences in the associations by number of births and gestational age, we constructed categorical variables combining the number of births (one vs. two or more) and pregnancy outcome (term and preterm with and without placental abruption). Preterm was defined as delivery in weeks 22 through 36 . We evaluated the statistical significance of interactions by creating cross-product terms between abruption and the modifier of interest and using the likelihood ratio test to compare the fit of models with and without the interaction term.

In our second set of analyses, we examined mortality risk in relation to placental abruption in any pregnancy, the 
total number of occurrences of abruption, and whether or not the woman also had preeclampsia in any of her pregnancies. These analyses were conducted using combined data from Norway and Sweden and were restricted to women with singleton births only $n=2,083,732$. We used Cox proportional-hazards regression with attained age as the primary time scale; women had delayed entry into risk sets (left-censored) at the year of their most recent birth because we were assessing exposures across reproductive history. The adjustment variables and follow up period were the same as the first series of analyses described above.

We used subsets of data available only in Norway or Sweden to further assess and adjust for possible confounding. Using information on 821,156 fathers in Norway, we examined abruption in first pregnancy and father's mortality risk. The objective was to assess the possible role of confounding by unmeasured social factors. Any association of father's mortality with abruption would presumably be unrelated to the physiologic effects of
Table 1 Maternal and pregnancy characteristics by occurrence of abruption in first pregnancy among women with singleton first births in Norway 1967-2002 and Sweden 1973-2003

\begin{tabular}{|c|c|c|c|c|}
\hline \multirow[t]{2}{*}{ Maternal and pregnancy characteristics } & \multicolumn{2}{|c|}{$\begin{array}{l}\text { Abruption in first pregnancy } \\
\mathrm{N}=10,981\end{array}$} & \multicolumn{2}{|c|}{$\begin{array}{l}\text { No abruption in first pregnancy } \\
\mathrm{N}=2,106,816\end{array}$} \\
\hline & Number & $\%$ & Number & $\%$ \\
\hline \multicolumn{5}{|l|}{ Age at first pregnancy (years) } \\
\hline$<20$ & 1170 & 10.7 & 218,846 & 10.4 \\
\hline $20-24$ & 3849 & 35.1 & 787,053 & 37.4 \\
\hline $25-29$ & 3537 & 32.2 & 719,829 & 34.2 \\
\hline $30-34$ & 1755 & 16.0 & 292,614 & 13.9 \\
\hline $35-39$ & 567 & 5.2 & 76,468 & 3.6 \\
\hline $40+$ & 103 & 0.9 & 12,003 & 0.6 \\
\hline Missing $^{\mathrm{a}}$ & 0 & & 3 & \\
\hline \multicolumn{5}{|l|}{ Education (years) } \\
\hline$<10$ & 2058 & 19.1 & 327,771 & 15.8 \\
\hline $10-12$ & 5146 & 47.7 & 975,121 & 47.1 \\
\hline $13-14$ & 1030 & 9.6 & 221,670 & 10.7 \\
\hline $15+$ & 2547 & 23.6 & 547,661 & 26.4 \\
\hline Missing $^{\mathrm{a}}$ & 200 & & 34,593 & \\
\hline \multicolumn{5}{|l|}{ Place of birth } \\
\hline Native to Norway or Sweden & 9773 & 89.7 & $1,862,732$ & 88.9 \\
\hline Other Nordic & 402 & 3.7 & 77,169 & 3.7 \\
\hline Other & 726 & 6.7 & 156,138 & 7.5 \\
\hline Missing $^{\mathrm{a}}$ & 80 & & 10,777 & \\
\hline \multicolumn{5}{|l|}{ Parity by end of follow-up } \\
\hline One child & 2366 & 21.6 & 370,494 & 17.6 \\
\hline Two or more & 8615 & 78.4 & $1,736,322$ & 82.4 \\
\hline Pre-gestational hypertension ${ }^{\mathrm{b}}$ & 43 & 0.4 & 4041 & 0.2 \\
\hline Pre-gestational diabetes ${ }^{\mathrm{b}}$ & 45 & 0.4 & 5223 & 0.4 \\
\hline Preterm delivery & 5263 & 49.8 & 122,544 & 6.0 \\
\hline Missing $^{\mathrm{a}}$ & 404 & & 50,170 & \\
\hline Gestational diabetes $^{\mathrm{b}}$ & 33 & 0.3 & 6234 & 0.3 \\
\hline Preeclampsia $^{\mathrm{b}}$ & 1106 & 10.1 & 80,868 & 3.8 \\
\hline Pregnancy-related hypertension ${ }^{\mathrm{b}, \mathrm{c}}$ & 118 & 2.5 & 14,266 & 1.7 \\
\hline Smoked during any pregnancy ${ }^{\mathrm{d}}$ & 1792 & 34.7 & 257,450 & 24.6 \\
\hline Missing & 1087 & & 229,132 & \\
\hline
\end{tabular}

${ }^{a}$ Missing values $<4 \%$

b Status during first pregnancy

c Norway only

d Sweden only, women with singleton births only, smoking information available 1983-onward, $18 \%$ missing values 
pregnancy. We used the same selection criteria and analytic strategy as for mothers, with father's attained age as the underlying time variable in the Cox proportional hazards models, left-censoring at the year of first delivery, and adjustment for father's age at the birth $(<20,20-24,25-29$, $30-34,35-39,40+$ years), year of first birth (linear term), and father's education ( 9 categories).

In Sweden, information on maternal smoking was ascertained by midwives at the time of the first prenatal care visit (occurring before the 15th week of gestation in over $95 \%$ of the pregnancies) and was available in the Medical Birth Register from 1983-onward. For our analysis of mortality risk, we were interested in women's smoking status and not the level of smoking in any particular pregnancy. To estimate this, we grouped women as nonsmokers (i.e., non-daily smokers) and smokers (i.e., daily smokers) at the first prenatal visit. To maximize the use of the available data, we examined smoking across all of each woman's pregnancies and categorized women as ever or never smokers, thus avoiding missing data for the women with first pregnancies before 1983 but who had later pregnancies with smoking information. Among the $1,034,049$ women with smoking data using this strategy, we assessed possible confounding by comparing estimates from models including and excluding the smoking variable in analyses examining abruption in any pregnancy and risk of maternal mortality.

\section{Results}

\section{Placental abruption in first pregnancy}

Among the 2,117, 797 women who had first deliveries during the study period, 10,981 $(0.5 \%)$ had placental abruption (Table 1). The mean follow up time was 25 years in Norway, 22 years in Sweden, and 23 years (range 1-42 years) in the combined material with a total of $48,786,382$ person-years at risk. There were $5453 \mathrm{CVD}$ deaths out of a total of 49,994 deaths during the follow up period (22,885 in Norway and 26,760 in Sweden). The median age at death was 48 years overall and 51 years for CVD deaths.

Associations between abruption in first pregnancy and mortality outcomes were generally similar for Norway and Sweden (Table 2); results of the combined analyses are reported here. Compared with women who did not experience placental abruption in first pregnancy, those who experienced placental abruption had an increased risk of CVD mortality (HR 1.8; 95 \% CI 1.3, 2.4). Risks were similar for the sub-categories of ischemic heart disease (HR 2.0; 1.4, 2.9) and cerebrovascular disease (HR 1.6; $1.0,2.4)$. Women with abruption also had a small increased risk of dying from non-CVD disease (HR 1.2; 1.0, 1.3). Increased risk of CVD mortality persisted after excluding women with chronic hypertension, chronic or gestational diabetes, preeclampsia, and pregnancy-related hypertension (Table 3).

For women with two or more pregnancies, abruption in the first pregnancy was associated with an increased risk of CVD mortality (HR 2.1; 1.5, 2.9) (Table 4). For women with one lifetime pregnancy, the increased risk of CVD mortality associated with abruption (HR 2.6; 1.5, 4.3) was only marginally increased above the CVD mortality risk associated with having only one pregnancy (HR 1.9; 1.8 , 2.1) (reference group women with two or more pregnancies and no abruption in first pregnancy). The interaction between number of pregnancies and abruption for CVD mortality was not statistically persuasive $(p$ value $=0.16$ ) The association between abruption and CVD mortality was present mainly in women who had preterm deliveries (HR 2.3; 1.6, 3.3 for abruption in preterm; HR 1.3; 0.8, 2.2 for abruption in term), however the interaction between preterm delivery and abruption for CVD mortality was not statistically persuasive ( $p$ value $=0.86$ ).

\section{Placental abruption in any pregnancy}

In analyses of placental abruption in any pregnancy, the mean follow up was 23 years (range 1-42 years) among $2,083,732$ women, contributing to $48,018,129$ person years at risk. A total of 23,529 women or $1.1 \%$ of the study population had placental abruption in any pregnancy. There were 5385 CVD deaths out of a total of 49,313 deaths during the follow up period. Compared with women who never experienced placental abruption, women who had placental abruption in at least one pregnancy had a 1.8-fold increased risk of CVD mortality (Table 5). The HR was slightly higher among the 782 women who had abruption in 2 or more pregnancies (HR 2.2; 0.8, 6.0) based on only 5 CVD deaths in the exposed group. Women who had abruption in 2 or more pregnancies also had an increased risk of dying from a non-CVD cause (HR 1.6; 1.1, 2.5). In conjoint analyses of placental abruption and preeclampsia in any pregnancy, there were increased risks of CVD mortality among women who had placental abruption only (HR 1.8; 1.4, 2.2), preeclampsia only (HR 1.9; 1.7, 2.1), and women experiencing both conditions in either the same or different pregnancies (HR 3.0; 1.9, 4.8) compared with women who had experienced neither.

\section{Father's analysis}

In the Norwegian data, the association between placental abruption in the first delivery and father's CVD mortality 


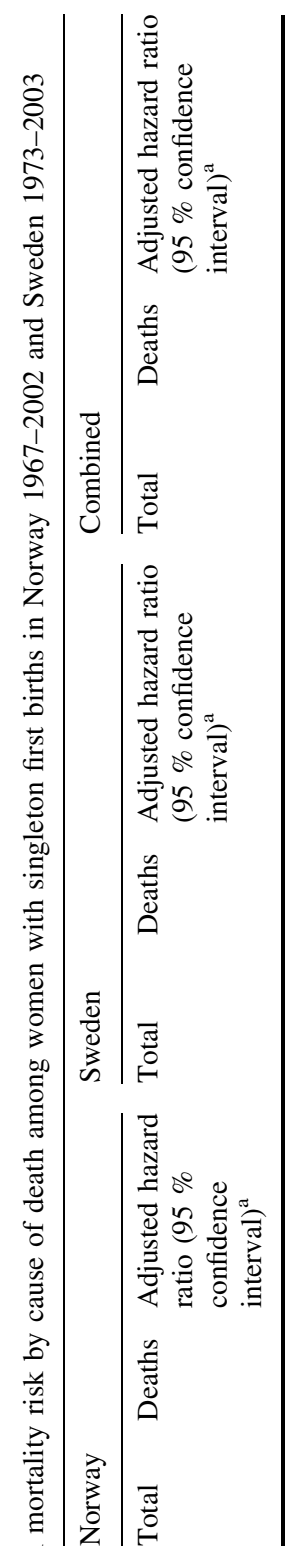

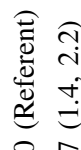

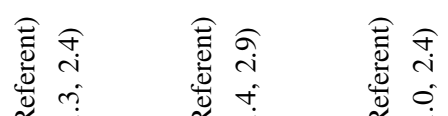

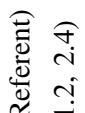

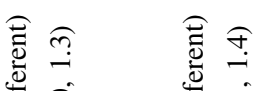

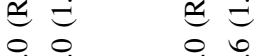

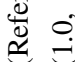

윽

$\stackrel{\infty}{\circ}$

우

오

오 눈

ลे

ले n

$\frac{n}{\sqrt{n}} \bar{m}$

๙ิ่

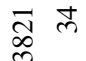

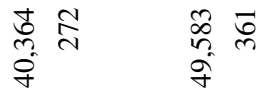

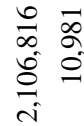

$\begin{array}{ll}0 & \bar{\infty} \\ \infty & 0 \\ 0 & 0 \\ 0 & 0 \\ i & \end{array}$

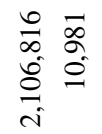

$\begin{array}{lll}0 & \infty & 0 \\ \infty & 0 \\ 0 & 0 & 0 \\ 0 & 0 & 0 \\ 0 & 0 & 0 \\ i & & 0\end{array}$

\begin{tabular}{l}
0 \\
0 \\
\hdashline
\end{tabular}

\begin{tabular}{ll}
0 & $\overline{0}$ \\
$\infty$ & 0 \\
8 & 0 \\
\hdashline & 0 \\
$i$ &
\end{tabular}

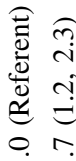

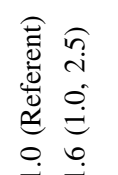

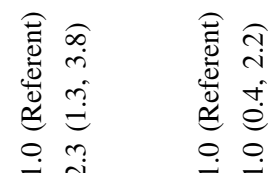

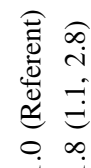

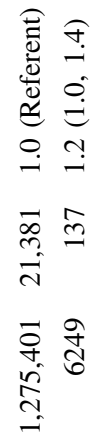

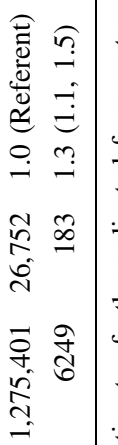

홈

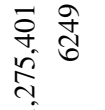

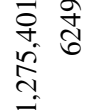

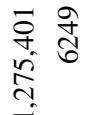

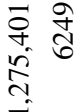

बิํํㄹำ

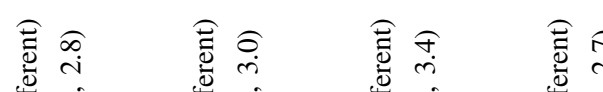

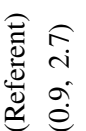

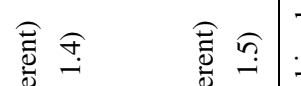

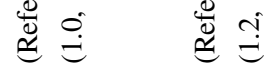

$\underset{8}{-\infty}$

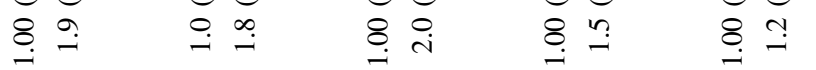

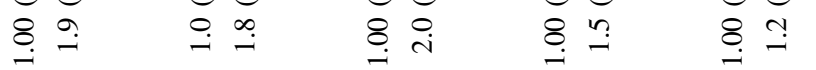

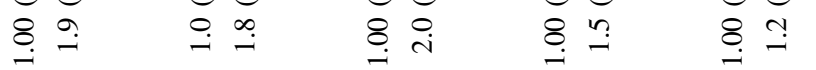

$\stackrel{0}{\mathscr{c}} \stackrel{0}{=}$

$\stackrel{\mathscr{e}}{\mathscr{2}} \cong$

을

$\underset{\substack{+\infty}}{\infty}$

तु

$\stackrel{\infty}{\stackrel{\Xi}{ }}$

$\stackrel{ }{\underline{I}}=$

तิ

$\infty$
$\infty$
$\infty$
$\infty$

$\begin{array}{ll}\vec{\infty} & \infty \\ \infty & \leq \\ \text { i } & \end{array}$

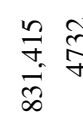

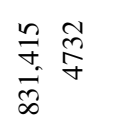

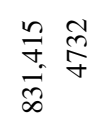

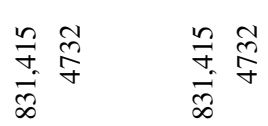

$\underset{\infty}{\stackrel{n}{*} \underset{\infty}{\sim}} \underset{\sim}{\sim}$

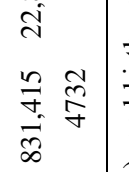

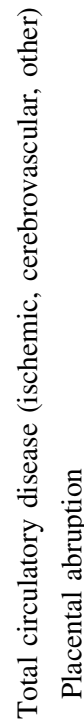<smiles>C1CC1</smiles>

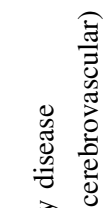

造

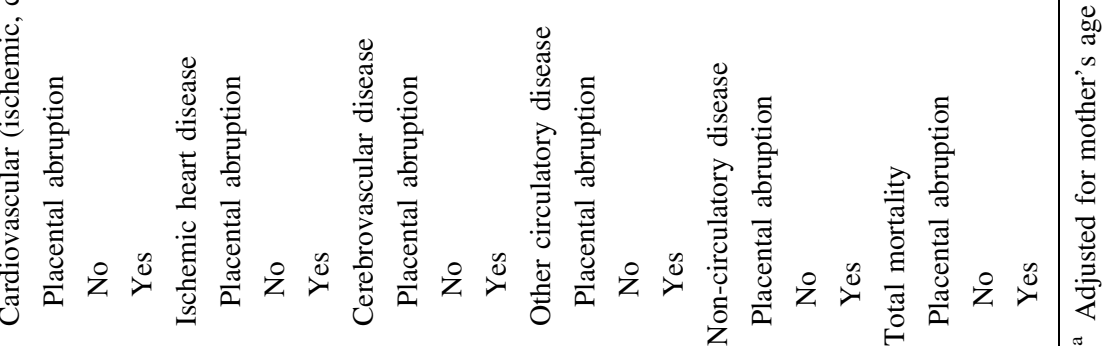


Table 3 Placental abruption in first pregnancy and long-term mortality risk among women with singleton first births in Norway 1967-2002 and Sweden 1973-2003

\begin{tabular}{|c|c|c|c|c|c|c|c|}
\hline \multirow{2}{*}{$\begin{array}{l}\text { Condition of first } \\
\text { pregnancy }\end{array}$} & \multirow{2}{*}{$\begin{array}{l}\text { Number of } \\
\text { women }\end{array}$} & \multicolumn{2}{|c|}{ Cardiovascular disease deaths } & \multicolumn{2}{|c|}{ Non-cardiovascular disease deaths ${ }^{\mathrm{a}}$} & \multicolumn{2}{|c|}{ Total deaths } \\
\hline & & Number & 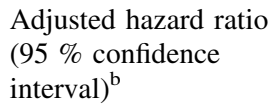 & Number & 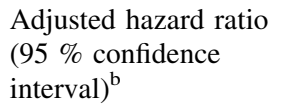 & Number & $\begin{array}{l}\text { Adjusted hazard ratio } \\
(95 \% \text { confidence } \\
\text { interval })^{\mathrm{b}}\end{array}$ \\
\hline \multicolumn{8}{|l|}{ Main analysis } \\
\hline \multicolumn{8}{|c|}{ Placental abruption } \\
\hline No & $2,106,816$ & 5398 & 1.0 (Referent) & 40,572 & 1.0 (Referent) & 49,583 & 1.0 (Referent) \\
\hline Yes & 10,981 & 55 & $1.8(1.3,2.4)$ & 273 & $1.2(1.0,1.3)$ & 361 & $1.3(1.1,1.4)$ \\
\hline \multicolumn{8}{|l|}{ Sub-analyses } \\
\hline \multicolumn{8}{|c|}{ Excluding women with chronic hypertension, pre-pregnancy or gestational diabetes, preeclampsia } \\
\hline \multicolumn{8}{|c|}{ Placental abruption } \\
\hline No & $2,012,488$ & 4941 & 1.0 (Referent) & 38,757 & 1.0 (Referent) & 47,264 & 1.0 (Referent) \\
\hline Yes & 9775 & 45 & $1.7(1.2,2.3)$ & 244 & $1.2(1.0,1.3)$ & 317 & $1.3(1.1,1.4)$ \\
\hline \multicolumn{8}{|c|}{ Norway only: excluding women with the above conditions plus pregnancy-related hypertension } \\
\hline \multicolumn{8}{|c|}{ Placental abruption } \\
\hline No & 777,977 & 2212 & 1.0 (Referent) & 17,868 & 1.0 (Referent) & 21,290 & 1.0 (Referent) \\
\hline Yes & 4091 & 23 & $1.8(1.2,2.8)$ & 117 & $1.2(1.0,1.4)$ & 149 & $1.3(1.1,1.5)$ \\
\hline
\end{tabular}

${ }^{a}$ Excluding all circulatory conditions

b Adjusted for mother's age at first birth, mother's education, birth year of child, and in analyses of combined data, country

Table 4 Placental abruption in first pregnancy and long-term mortality risk by number of pregnancies among women with singleton first births in Norway 1967-2002 and Sweden 1973-2003

\begin{tabular}{|c|c|c|c|c|c|c|c|}
\hline \multirow[t]{2}{*}{ Condition of first pregnancy } & \multirow[t]{2}{*}{$\begin{array}{l}\text { Number of } \\
\text { women }\end{array}$} & \multicolumn{2}{|c|}{$\begin{array}{l}\text { Cardiovascular disease } \\
\text { deaths }\end{array}$} & \multicolumn{2}{|c|}{$\begin{array}{l}\text { Non-cardiovascular disease } \\
\text { deaths }^{\mathrm{a}}\end{array}$} & \multicolumn{2}{|c|}{ Total deaths } \\
\hline & & Number & $\begin{array}{l}\text { Adjusted } \\
\text { hazard } \\
\text { ratio }(95 \% \\
\text { confidence } \\
\text { interval) }^{\text {b }}\end{array}$ & Number & $\begin{array}{l}\text { Adjusted } \\
\text { hazard } \\
\text { ratio }(95 \% \\
\text { confidence } \\
\text { interval) }^{\mathrm{b}}\end{array}$ & Number & $\begin{array}{l}\text { Adjusted } \\
\text { hazard } \\
\text { ratio (95\% } \\
\text { confidence } \\
\text { interval) }^{\mathrm{b}}\end{array}$ \\
\hline \multicolumn{8}{|c|}{ Placental abruption by no. lifetime pregnancies } \\
\hline No abruption $-2+$ pregnancies & $1,736,322$ & 3429 & 1.0 (Referent) & 27,529 & 1.0 (Referent) & 33,329 & 1.0 (Referent) \\
\hline Abruption $-2+$ pregnancies & 8615 & 35 & $2.1(1.5,2.9)$ & 172 & $1.2(1.0,1.4)$ & 227 & $1.3(1.1,1.5)$ \\
\hline No abruption-1 pregnancy & 370,494 & 1969 & $1.9(1.8,2.1)$ & 12,835 & $1.7(1.7,1.7)$ & 16,254 & $1.7(1.7,1.8)$ \\
\hline Abruption - 1 pregnancy & 2366 & 20 & $2.6(1.5,4.3)$ & 100 & $2.0(1.6,2.5)$ & 134 & $2.2(1.8,2.6)$ \\
\hline $\begin{array}{l}\text { Interaction abruption } \times \text { no. of } \\
\text { pregnancies }\end{array}$ & & & $p$ value $=0.16$ & & $p$ value $=0.97$ & & $p$ value $=0.84$ \\
\hline \multicolumn{8}{|l|}{ Placental abruption by preterm } \\
\hline No abruption-term & $1,934,102$ & 4632 & 1.0 (Referent) & 36,263 & 1.0 (Referent) & 44,230 & 1.0 (Referent) \\
\hline Abruption-term & 5314 & 21 & $1.3(0.8,2.2)$ & 122 & $1.1(0.9,1.3)$ & 161 & $1.2(1.0,1.4)$ \\
\hline No abruption-preterm & 122,544 & 600 & $1.8(1.7,2.0)$ & 2968 & $1.2(1.2,1.3)$ & 3953 & $1.3(1.3,1.4)$ \\
\hline Abruption-preterm & 5263 & 30 & $2.3(1.6,3.3)$ & 138 & $1.3(1.1,1.5)$ & 184 & $1.4(1.2,1.6)$ \\
\hline Interaction abruption $\times$ preterm & & & $p$ value $=0.86$ & & $p$ value $=0.64$ & & $p$ value $=0.29$ \\
\hline
\end{tabular}

${ }^{a}$ Excluding all circulatory conditions

b Adjusted for mother's age at first birth, mother's education, birth year of child and country 
Table 5 Placental abruption in any pregnancy and long-term mortality risk among women with first singleton births in Norway 1967-2002 and Sweden 1973-2003

\begin{tabular}{|c|c|c|c|c|c|c|c|}
\hline & \multirow[t]{2}{*}{ Number } & \multicolumn{2}{|c|}{ Cardiovascular disease deaths } & \multicolumn{2}{|c|}{ Non-cardiovascular disease deaths ${ }^{\mathrm{a}}$} & \multicolumn{2}{|c|}{ Total deaths } \\
\hline & & Number & $\begin{array}{l}\text { Adjusted hazard } \\
\text { ratio }(95 \% \\
\text { confidence } \\
\text { interval) }^{\mathrm{b}}\end{array}$ & Number & $\begin{array}{l}\text { Adjusted hazard } \\
\text { ratio }(95 \% \\
\text { confidence } \\
\text { interval) }^{\mathrm{b}}\end{array}$ & Number & $\begin{array}{l}\text { Adjusted hazard } \\
\text { ratio }(95 \% \\
\text { confidence } \\
\text { interval })^{\mathrm{b}}\end{array}$ \\
\hline \multicolumn{8}{|l|}{ Placental abruption } \\
\hline Never & $2,060,203$ & 5272 & 1.0 (Referent) & 39,557 & 1.0 (Referent) & 48,573 & 1.0 (Referent) \\
\hline Ever & 23,529 & 113 & $1.8(1.5,2.2)$ & 562 & $1.2(1.1,1.3)$ & 740 & $1.3(1.2,1.4)$ \\
\hline \multicolumn{8}{|l|}{ No. of times } \\
\hline Never & $2,060,203$ & 5272 & 1.0 (Referent) & 39,557 & 1.0 (Referent) & 48,573 & 1.0 (Referent) \\
\hline 1 & 22,747 & 108 & $1.8(1.5,2.2)$ & 535 & $1.2(1.1,1.3)$ & 706 & $1.3(1.2,1.4)$ \\
\hline $2+$ & 782 & 5 & $2.2(0.8,6.0)$ & 27 & $1.6(1.1,2.5)$ & 34 & $1.7(1.2,2.5)$ \\
\hline \multicolumn{8}{|c|}{ Placental abruption and preeclampsia/eclampsia } \\
\hline Never had either & $1,950,617$ & 4790 & 1.0 (Referent) & 37,751 & 1.0 (Referent) & 46,026 & 1.0 (Referent) \\
\hline Placental abruption only & 20,701 & 95 & $1.8(1.4,2.2)$ & 505 & $1.2(1.1,1.3)$ & 654 & $1.3(1.2,1.4)$ \\
\hline Preeclampsia only & 109,586 & 482 & $1.9(1.7,2.1)$ & 1806 & $0.9(0.9,1.0)$ & 2547 & $1.1(1.0,1.1)$ \\
\hline Both & 2828 & 18 & $3.0(1.9,4.8)$ & 57 & $1.1(0.8,1.4)$ & 86 & $1.3(1.1,1.7)$ \\
\hline
\end{tabular}

Excluding women with multiple gestations in any pregnancy

${ }^{a}$ Excluding all circulatory conditions

b Adjusted for mother's age at first birth, mother's education, birth year of child and country

was small and did not reach statistical significance (HR $1.2 ; 0.9,1.5)$.

\section{Adjustment for maternal smoking}

In the subset of Swedish data with available smoking information from 1983-onward, maternal smoking was associated with both non-CVD mortality (HR $1.7 ; 1.7,1.8$ ) and CVD mortality (HR 2.9; 2.5, 3.3). Without adjustment for smoking, the association between abruption in any pregnancy and risk of maternal CVD mortality was HR $=2.0$ $(1.3,2.3)$ after adjusting for maternal age, education and year of first birth. Further adjustment for maternal smoking attenuated this association (HR 1.7; 1.2, 2.5).

\section{Discussion}

In this large, population-based study, women with placental abruption in the first or a later pregnancy had a 1.8fold increased risk of CVD mortality later in life. The magnitude of the association is similar to that of current smoking and CVD mortality in women [21, 22]. This study adds to the growing evidence that pregnancy complications may predict later CVD and help target women for primary prevention [23]. It is unclear whether the metabolic, inflammatory and hemodynamic demands of pregnancy unmask underlying phenotypic susceptibility to CVD expressed through pregnancy complications or if the complicated pregnancy itself induces vascular damage or inflammatory or other responses that increase CVD risk [24]. Following a complicated pregnancy, postpartum referral by obstetricians to primary-care physicians or cardiologists for monitoring and controlling CVD risk factors would allow women of child-bearing age to begin preventive efforts early in life and reduce the risk of CVD. The American Heart Association recently incorporated history of preeclampsia, gestational diabetes, and pregnancy-induced hypertension into its CVD risk-assessment guidelines for women [25]. Placental abruption should be considered for inclusion as an additional risk factor.

There was a suggestion in our data of a stronger effect of abruption among women who had two or more pregnancies and those with preterm deliveries. However, these interactions lacked statistical strength, which limits our ability to interpret them. Women with only one pregnancy already have a strongly increased risk of CVD mortality (as has been reported earlier [9]), which may make the further influence of abruption difficult to detect. Vaginal bleeding caused by placental abruption is associated with a high risk of preterm delivery [26]. The occurrence of abruption may necessitate or provoke the delivery of the infant early in gestation [27]. In our study, about half of the women with abruption in first pregnancy had pregnancies ending in preterm delivery. Preterm delivery itself is associated with increased risk of maternal CVD [28, 29], suggesting that it 
may be in the causal pathway for the association between abruption and CVD mortality.

The results of the father's analysis provide some assurance that our main findings in mothers were not primarily due to unmeasured confounding of lifestyle variables. There was evidence of a small increased risk of paternal CVD mortality for first-pregnancy abruption (although confidence intervals included one), suggesting that our findings may have a small degree of confounding by unmeasured social factors or CVD risk factors, such as cigarette smoking, that have a high concordance in partners $[30,31]$. In our sub-analysis of Swedish data, adjustment for maternal smoking left most of the association between abruption and maternal CVD mortality, although our smoking data were limited to information collected at the first prenatal care visit and residual confounding is still possible. To the extent that smokers were misclassified in our sub-analysis, the association between abruption and risk of CVD mortality may be overestimated.

The increased risk for non-CVD mortality among women who experienced abruption in two or more pregnancies is notable. Among the 34 women with recurrent abruption who died of non-CVD causes, $18 \%$ had drug or alcohol-related deaths compared with only $6 \%$ of the deaths among women without abruption. Injury-related deaths, including suicide, were also increased (29 vs. $16 \%$ ), but not cancer deaths (32 vs. $52 \%$ ). This suggests that the increased risk of non-CVD mortality among women with recurrent abruption was due, at least in part, to drug or alcohol abuse, factors also related to increased risk of abruption.

The prevalence of abruption in our study is similar to that of other epidemiologic studies relying on clinical diagnosis. Placental abruption has not been validated in the Norway Birth Registry, but a 1986 validation study in Sweden found good correspondence between the diagnosis of abruption as reported by ICD codes in the birth registry and the description of clinical abruption documented in individual delivery records [32]. In the United States, two validation studies comparing state birth certificates with medical records found $>99 \%$ specificity and moderate sensitivity for abruption, as would be expected for a rare condition [33, 34]. This suggests that studies using vital statistics registries are subject to under-ascertainment of rare conditions such as abruption but have negligible numbers of false positives. With the assumption that exposure misclassification is non-differential in regard to outcome, which seems reasonable in our study because the collection of exposure data in registries predated the outcome, any bias produced by exposure misclassification would tend to be toward the null.

The strengths of this study include the use of populationbased registry data from two Nordic countries, which enabled a large study size, prospective data collection, the study of complete reproductive history, and nearly complete ascertainment of mortality. Limitations of the study include a lack of detailed information on underlying cardiovascular risk factors before and after pregnancy. We also lacked information on the severity of the abruption and could not differentiate between mild cases and the more serious manifestations. Even in our study of over 2 million women, we had small numbers of women for some of the exposures of interest, particularly recurrent abruption, which limited our statistical power in some analyses. Although we lacked information on maternal smoking for the full study, we were able to use available Swedish data to adjust for smoking in sub-analyses. However, there is likely some misclassification of smoking in these analyses; for example, women who smoked either before or after their pregnancies but abstained during pregnancy would have been misclassified as non-smokers in our study. Even with an average of 23 years of follow-up, the women in this study were relatively young at the end of follow up. The CVD deaths that occurred at a relatively young age among women with abruption may reflect the most severe cases of the condition, and therefore the associations between abruption and risk of CVD mortality may attenuate as the follow up period increases over time, as observed in a study of preeclampsia [9].

Two previous studies examined placental abruption and long-term maternal CVD mortality. A large registry-based study in Denmark of 782,287 women with singleton deliveries 1978-2007 (7684 with abruption) and a median follow-up of 14.8 years found a weakly increased risk of CVD mortality for women with abruption (HR 1.23; 0.78, 1.93) [35]. Their CVD endpoint differed from ours; along with a CVD cause of death stated in the Cause of Death Registry, they also included a first clinical diagnosis of CVD (e.g., de novo hypertension) within 1 week prior to death. If their broader definition resulted in misclassification of non-CVD deaths as CVD deaths, then the resulting bias would tend to be towards the null. An Israeli study examined CVD mortality among 47,585 women (653 with abruption) who gave birth in a large medical center during 1988-1999 with a median follow up of 13.8 years [36]. They found an increased risk of CVD mortality for women with abruption (HR 4.3; 1.1-18.6). This hospital-based study lacked information on CVD mortality outside of the medical center and the small numbers of outcomes (only 6 CVD deaths among exposed women) contributed to imprecise estimates. Our use of registry data from two countries allowed population-based ascertainment of CVD deaths and provided a larger sample of women and longer follow-up time than these previous studies.

In summary, we found evidence that placental abruption, like other placental complications of pregnancy, is 
associated with women's increased risk of later CVD mortality. Pregnancy complications occur at an early phase of life when targeted prevention may allow women to avoid CVD through lifestyle changes or preventive medicine. It is currently unknown whether traditional prevention measures will be effective in reducing long-term CVD risk in this population of women [37]. The feasibility of changing the course of women's CVD risk after placental complications of pregnancy should be explored.

Acknowledgments This research was supported by the Norwegian Research Council, the European Union's Seventh Framework Program (FP2007-2001; under Grant Agreement 259679), and the Intramural Research Program of the NIH, National Institute of Environmental Health Sciences. We thank Drs. Donna Baird and Anne Marie Z. Jukic for providing helpful comments on this manuscript.

\section{Compliance with Ethical Standards}

Conflict of interest None to declare.

Ethical approval All procedures performed in studies involving human participants were in accordance with the ethical standards of the institutional and/or national research committee and with the 1964 Helsinki declaration and its later amendments or comparable ethical standards. For this type of study formal consent is not required.

Open Access This article is distributed under the terms of the Creative Commons Attribution 4.0 International License (http://creati vecommons.org/licenses/by/4.0/), which permits unrestricted use, distribution, and reproduction in any medium, provided you give appropriate credit to the original author(s) and the source, provide a link to the Creative Commons license, and indicate if changes were made.

\section{References}

1. World Health Organization. Fact sheet 334: women's health. Geneva. 2013. http://www.who.int/mediacentre/factsheets/fs334/en/.

2. Wenger NK. What do the 2011 American Heart Association guidelines tell us about prevention of cardiovascular disease in women? Clin Cardiol. 2011;34(9):520-3.

3. Stock EO, Redberg R. Cardiovascular disease in women. Curr Probl Cardiol. 2012;37(11):450-526.

4. Sattar N, Greer IA. Pregnancy complications and maternal cardiovascular risk: opportunities for intervention and screening? BMJ. 2002;325(7356):157-60.

5. Rich-Edwards JW. Reproductive health as a sentinel of chronic disease in women. Womens Health. 2009;5(2):101-5.

6. Bellamy L, Casas JP, Hingorani AD, Williams DJ. Pre-eclampsia and risk of cardiovascular disease and cancer in later life: systematic review and meta-analysis. BMJ. 2007;335(7627):974.

7. Brown MC, Best KE, Pearce MS, Waugh J, Robson SC, Bell R. Cardiovascular disease risk in women with pre-eclampsia: systematic review and meta-analysis. Eur J Epidemiol. 2013;28(1):1-19.

8. Ahmed R, Dunford J, Mehran R, Robson S, Kunadian V. Preeclampsia and future cardiovascular risk among women: a review. J Am Coll Cardiol. 2014;63(18):1815-22.

9. Skjaerven R, Wilcox AJ, Klungsoyr K, Irgens LM, Vikse BE, Vatten LJ, et al. Cardiovascular mortality after pre-eclampsia in one child mothers: prospective, population based cohort study. BMJ. 2012;345:e7677.

10. Tikkanen M. Placental abruption: epidemiology, risk factors and consequences. Acta Obstet Gynecol Scand. 2011;90(2):140-9.

11. Ananth CV, Wilcox AJ. Placental abruption and perinatal mortality in the United States. Am J Epidemiol. 2001;153(4):332-7.

12. Spinillo A, Capuzzo E, Colonna L, Solerte L, Nicola S, Guaschino S. Factors associated with abruptio placentae in preterm deliveries. Acta Obstet Gynecol Scand. 1994;73(4):307-12.

13. Ananth CV, Smulian JC, Demissie K, Vintzileos AM, Knuppel RA. Placental abruption among singleton and twin births in the United States: risk factor profiles. Am J Epidemiol. 2001;153(8): 771-8.

14. Dommisse J, Tiltman AJ. Placental bed biopsies in placental abruption. Br J Obstet Gynaecol. 1992;99(8):651-4.

15. Brosens I, Pijnenborg R, Vercruysse L, Romero R. The, "Great Obstetrical Syndromes" are associated with disorders of deep placentation. Am J Obstet Gynecol. 2011;204(3):193-201.

16. Ananth CV. Ischemic placental disease: a unifying concept for preeclampsia, intrauterine growth restriction, and placental abruption. Semin Perinatol. 2014;38(3):131-2.

17. Irgens LM. The Medical Birth Registry of Norway. Epidemiological research and surveillance throughout 30 years. Acta Obstet Gynecol Scand. 2000;79(6):435-9.

18. Centre for Epidemiology, The National Board of Health and Welfare of Sweden. The Swedish medical birth register-a summary of content and quality Contract No.: Article no: 2003-112-3.

19. Korn EL, Graubard BI, Midthune D. Time-to-event analysis of longitudinal follow-up of a survey: choice of the time-scale. Am J Epidemiol. 1997;145(1):72-80.

20. Thiebaut AC, Benichou J. Choice of time-scale in Cox's model analysis of epidemiologic cohort data: a simulation study. Stat Med. 2004;23(24):3803-20.

21. Omenn GS, Anderson KW, Kronmal RA, Vlietstra RE. The temporal pattern of reduction of mortality risk after smoking cessation. Am J Prev Med. 1990;6(5):251-7.

22. LaCroix AZ, Lang J, Scherr P, Wallace RB, Cornoni-Huntley J, Berkman L, et al. Smoking and mortality among older men and women in three communities. N Engl J Med. 1991;324(23): 1619-25.

23. Rich-Edwards JW, Fraser A, Lawlor DA, Catov JM. Pregnancy characteristics and women's future cardiovascular health: an underused opportunity to improve women's health? Epidemiol Rev. 2014;36(1):57-70.

24. Wenger NK. Recognizing pregnancy-associated cardiovascular risk factors. Am J Cardiol. 2014;113(2):406-9.

25. Mosca L, Benjamin EJ, Berra K, Bezanson JL, Dolor RJ, LloydJones DM, et al. Effectiveness-based guidelines for the prevention of cardiovascular disease in women-2011 update: a guideline from the american heart association. Circulation. 2011; 123(11):1243-62.

26. Goldenberg RL, Culhane JF, Iams JD, Romero R. Epidemiology and causes of preterm birth. Lancet. 2008;371(9606):75-84.

27. Oyelese Y, Ananth CV. Placental abruption. Obstet Gynecol. 2006;108(4):1005-16.

28. Bonamy AK, Parikh NI, Cnattingius S, Ludvigsson JF, Ingelsson E. Birth characteristics and subsequent risks of maternal cardiovascular disease: effects of gestational age and fetal growth. Circulation. 2011;124(25):2839-46.

29. Rich-Edwards JW, Klungsoyr K, Wilcox AJ, Skjaerven R. Duration of pregnancy, even at term, predicts long-term risk of coronary heart disease and stroke mortality in women: a population-based study. Am J Obstet Gynecol. 2015. doi:10.1016/j. ajog.2015.06.001. 
30. Homish GG, Leonard KE. Spousal influence on smoking behaviors in a US community sample of newly married couples. Soc Sci Med. 2005;61(12):2557-67.

31. Di Castelnuovo A, Quacquaruccio G, Donati MB, de Gaetano G, Iacoviello L. Spousal concordance for major coronary risk factors: a systematic review and meta-analysis. Am J Epidemiol. 2009;169(1):1-8.

32. Karegard M, Gennser G. Incidence and recurrence rate of abruptio placentae in Sweden. Obstet Gynecol. 1986;67(4): 523-8.

33. Reichman NE, Hade EM. Validation of birth certificate data. A study of women in New Jersey's HealthStart program. Ann Epidemiol. 2001;11(3):186-93.

34. Roohan PJ, Josberger RE, Acar J, Dabir P, Feder HM, Gagliano PJ. Validation of birth certificate data in New York State. J Community Health. 2003;28(5):335-46.
35. Lykke JA, Langhoff-Roos J, Lockwood CJ, Triche EW, Paidas MJ. Mortality of mothers from cardiovascular and non-cardiovascular causes following pregnancy complications in first delivery. Paediatr Perinat Epidemiol. 2010;24(4):323-30.

36. Pariente G, Shoham-Vardi I, Kessous R, Sherf M, Sheiner E. Placental abruption as a significant risk factor for long-term cardiovascular mortality in a follow-up period of more than a decade. Paediatr Perinat Epidemiol. 2014;28(1):32-8.

37. Seely E, Tsigas E, Rich-Edwards JW. Preeclampsia and future cardiovascular disease in women: how good are the data and how can we manage our patients? Semin Perinat. 2015. doi:10.1053/j. semperi.2015.05.006. 